\title{
Automation of Department Library System
}

\author{
Dayanand G Savakar ${ }^{1}$, Ravi Hosur ${ }^{2}$ \\ ${ }^{1}$ Rani Chennamma University, Belagavi \\ ${ }^{2}$ BLDEA's Vachana Pitamaha Dr. P.G.Halaktti College of Engg. \& Tech, Bijapur
}

\begin{abstract}
The System is planned to be designed \& developed with a less storage space utilization, and perform the operations like issuing of books in the library, borrowing books from library, adding new books, updating existing book details, also managing the students' details and generate reports. The system (library management system) is planned to be register less which helps admin to perform all the activities related to library in an efficient manner within limited period of time. Students' need to register themselves to borrow books from library, students can search for available books so that they request to borrow that book from library. Every transaction between the student and the library will documented through the built-in database connections, and provides authenticated and authorized transactions.
\end{abstract}

Keywords: Storage, Books, Library, Transaction, System

\section{Introduction}

The existing system is a register based data entry system. It is tedious and requires time to maintain the information of books, Journal papers, etc., for borrowing and issuing of books, and searching them to get the information of books available in the library such as availability of books of particular author, particular publisher and particular book title, to get the information about details of students who have borrowed the books from library.

The library system existing has the maintenance through a manual based or register based. It takes longer time for searching, editing or updating, etc. To avoid such circumstances, the design of current system enables us to maintain records of books in the library like issuing of books, availability, or returning of books etc. at the faster rate compared to existing system. Also it consumes less human interpretation works that is proportional to less resource (cost) wastage.

The project titled Library Management System is management software for monitoring and controlling the transactions in a library. The project "Library Management System" is developed in dot net, which mainly focuses on basic operations in a library like adding new member, new books, and updating new information, Searching books and facility to borrow and return books.

Library Management System is a program that helps to manage time like the student first checks for availability then asks for issuing of book. Admin has the ability to store the results in a database, generate the reports, and add the new books, add the books categories, update the old books and store results.

\section{Review of Literature}

The method [1], witness's huge notice and a wealth of assure in content-based image recovery as a rising technology. It also a horizontal way for a huge number of new techniques and systems, get various new citizens include. In this piece, we survey almost 300 new hypothetical and experimental charity in the existing decade related to image recovery and regular image clarification. We also discuss significant challenges involved in the difference of existing image recovery techniques to build systems that can be useful in the genuine world. In retrospect of what has been achieved so far, we also work out what the prospect may hold for image recovery study.

Predictable methods [2] of image revival require that metadata is connected with the image, usually known as keywords. Though some content based image retrieval systems utilize together semantic and prehistoric attributes to relation search principle, history has proven that it is tricky to remove linguistic in sequence from a $2 \mathrm{D}$ picture. In this observe, activity theory is used as a foundation to express how semantic in sequence can be retrieved from objects recognized in a picture. Via an picture segmentation method.

By The Berkeley Digital Library Project, and merge it with, a high-level accepting of he picture can be established Content-Based Image Retrieval [3] has become one of the popular most research areas. Many diagram attribute representations contain been explored and many systems build. While, these research information found the foundation of satisfied based image recovery, the kindness of the future approaches is incomplete. Specially, these efforts have comparatively overlooked two different characteristics of systems the space between towering level concepts and low level skin texture bias of human compassion of visual content. Which electively takes into account the above two uniqueness in CBIR. During the recovery process, the user's high level query and insight partisanship are captured by dynamically updated weights based on the user's advice. The provisional results over more than 70,000 images show that the future approach greatly reduces the user's effort of composing a doubt and capture the user's in sequence.

Application feedback [4] scheme based on support vector equipment have been generally used in content-based image retrieval. However, the arrangement of based application criticism is frequently abridged when the figure of labeled 


\section{International Journal of Science and Research (IJSR) \\ ISSN (Online): 2319-7064}

Index Copernicus Value (2013): 6.14 | Impact Factor (2015): 6.391

positive advice sample is little. This is mostly due to three reasons a classifier is disturbed on a little sized teaching locate, and over suitable happens since the number of characteristic dimensions is much senior than the size of the preparation set. In this document, we expand a device to overcome these troubles. To speak to the first two troubles, we propose an asymmetric container based. For the third problem, we combine the random subspace method and SVM for application feedback, which is named random subspace SVM (RS-SVM). Finally, by AB-SVM and RSSVM, an asymmetric bag and accidental subspace SVM (ABRS-SVM) is build to solve these three problems and further improve the application feedback performance. Some researchers used Image processing techniques for security[5][6] and for agriculture and horticulture produce[7][8].

\section{Proposed System}

Department library management system is a standalone application which refers to small library systems which are generally large. It is used by librarian to manage the library using a computerized system where admin can do various transaction like issue of books, return of books.

\section{Process}

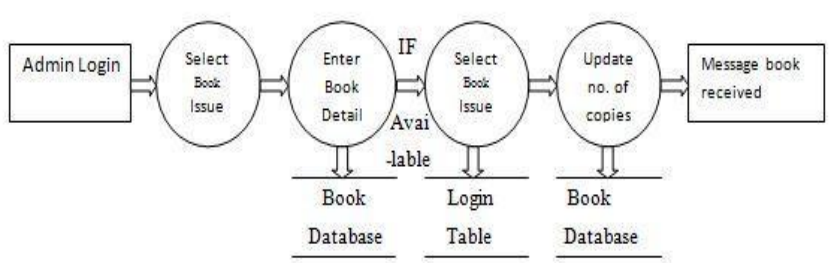

Figure 1: Cloud Computing. [courtesy: Wikipedia.com]

Implementation is the realization of an application, or execution of a plan. Our application is implemented according to three tier architecture as shown in below figure 5.1 Three tier architecture is commonly known as ClientServer architecture, where Client is the consumer of the services, also the requester of services whereas the server side is the provider of services. The third layer that is the middle layer that converts the users requests into server understandable form.

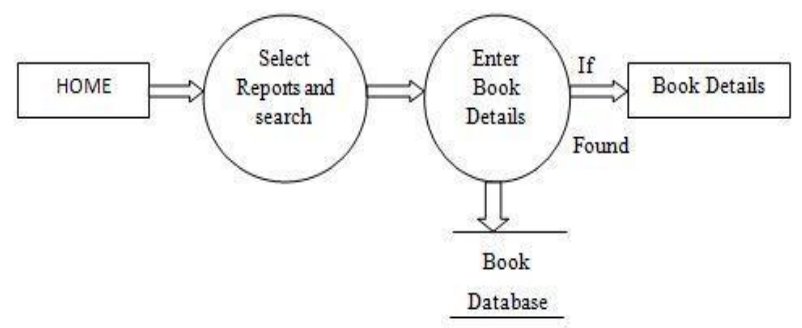

Figure 2: Automated System for Allocation using Cloud

Above system of allocation is useful for allocating students and faculty for any institute. Which can be integrated with cloud to yield more feasible solution from it. So that it is available to every institute which fall under same university. Where automated system is stored at cloud for the accessibility for every institute so that each institute can access the system remotely and get the result with few mouse clicks.

System testing is one of the important stages in the system development life cycle. It is essential to check whether the developed system is working properly according generic type of data inputs or not, or at what stage it is having problem to execute the particular problem and error searching for the different sets of conditions under any condition whenever the user gives proper inputs to test the program.

The testing commences with the test plans and terminates with the acceptance testing. Testing is applied at different levels in the Software Development Life Cycle. The purpose of all testing is to find errors at different levels.

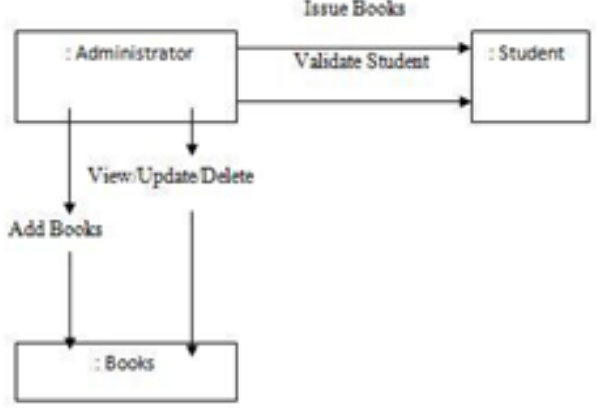

The UML Collaboration Diagram is used to form how objects involved in the scenario, to interact with each object instantiating with a particular class in the scheme. The Objects are usually connected by the links, where each link is representing an instance of an association between the respective classes involved. The link shows the messages sent between the objects, and type of the message is passed (synchronous, synchronous, simple, balking and timeout).

Collaboration diagram offers a better view of scenario than the Sequence diagram when the modular is trying to understand all the effects on a given object and are therefore good for procedural design. The Collaboration Diagram is very understandable compare to the sequence diagram as shown below.

\section{Users}

Library Management System basically has two main modules for proper functioning.

- First module is admin module in which he verifies student's registration details and approves students so that student can borrow books from library. Admin can add new books, update existing book details and generate reports and issue books to the students. Admin can view existing and issued book details.

- Second module is student module in which students can register themselves for borrowing books from the library. Students can search the books in the library and request books to the librarian.

\section{Conclusion}

The proposed idea greatly reduces the manpower error and time consumption. It benefits the all the institute by reducing the complexity involved in the allocation of exam duty. As all the work of allocation of exam duty is automated and

\section{Volume 5 Issue 6, June 2016 www.ijsr.net}




\section{International Journal of Science and Research (IJSR) \\ ISSN (Online): 2319-7064}

Index Copernicus Value (2013): 6.14 | Impact Factor (2015): 6.391

also faculties are allocated automatically. The percentage of doing mistakes will be reduced.

The system is developed using ASP.NET Using C\# fully meets the objectives of the system which it has been developed. The system has reached a steady state where all bugs have been eliminated. The system is operated at a high level of efficiency and all the teachers and user associated with the system understands its advantage. The system solves the problem. It was intended to solve as requirement specification.

\section{Future Enhancement}

The system can be further improved by adding more number of functionalities such as sending reminders through SMS/Email. With the help of Barcode scanning system the application can be further improved.

\section{References}

[1] R. Datta, D. Joshi, and J.Z. Wang (2007), "Image Retrieval: Ideas, Influences, and Trends" ACM Computing Surveys, vol. 40, article 5

[2] A.W.M. Smeulders, M. Worring, S. Santini, A. Gupta, and R. Jain (2000), "Content-Based Image Retrieval," IEEE Trans. Pattern Analysis and Machine Intelligence, vol. 22, no. 12, pp. 1349-1380

[3] Y. Rui, T.S. Huang, M. Ortega, and S. Mehrotra(1998), "Relevance Feedback: A Power Tool for Interactive Content-Based Image Retrieval," IEEE Trans. Circuits and Systems for Video Technology, vol. 8, no. 5, pp. 644-655

[4] X.S. Zhou and T.S. Huang (2003), "Relevance Feedback in Image Retrieval: A Comprehensive Review," Multimedia Systems, vol. 8,pp. 536-544D.G.Savakar, Anand Ghuli (2015), "Digital Watermarking A Combined Approach by DWT, Chirp-Z and Fast WalshHadamard Transform”, IJCTA, Vol. 5 No.6, pp 20062010.

[5] D.G.Savakar, Anand Ghuli (2015), "Digital Watermarking as a distributed noise by Discrete Wavelet Transformation, Fast Fourier Transformation and Fast Walsh-Hadamard Transform to study the sensitivity between Robustness and Fidelity", IJCA, Issue 1, Volume 5, pp 102-107

[6] Dayanand G. Savakar (2012), Identification and Classification of Bulk Fruits Images using Artificial Neural Networks. International Journal of Engineering and Innovative Technology (IJEIT), Volume 1, Issue 3, Pages: $35-40$

[7] Dayanand G. Savakar (2012), Recognition and Classification of Similar Looking Food Grain Images using ANN, Journal of Applied Computer Science and Mathematics ,Volume 13(6), Pages: 61- 65

Volume 5 Issue 6, June 2016 www.ijsr.net 